\title{
Suppressive Effect In Vitro of Magnesium L-Ascorbyl-2-phosphate (APM), an Ascorbic Acid Derivative, on the Impairment of DNA by Glucose-6-phosphate
}

\author{
Takashi Ano, Akihiro Orno and Makoto SHoda \\ Research Laboratory of Resources Utilization, Tokyo Institute of Technology, \\ 4259 Nagatsuta, Midori-ku, Yokohama 227, Japan
}

Received May 29, 1991

\begin{abstract}
We attempted to find compounds that suppress the DNA impairment caused by Dglucose-6-phosphate (Glc-6-P) by observing the Ioss of ability of pBR322 to transform Escherichia coli, and found that APM (magnesium L-ascorbyl-2-phosphate) suppressed the loss of transformability to less than 1/100 of that in the absence of APM. When 2'-deoxyguanosine 5'-monophosphate (dGMP) was incubated in the dark with Glc-6-P and APM, changes in their absorbance patterns were observed, indicating possible suppression by APM of the interactions between dGMP and Glc-6-P. APM weakly suppressed the Maillard reaction.
\end{abstract}

The Maillard reaction ${ }^{1)}$ is the nonenzymatic addition of reducing sugars to the amino groups of proteins and peptides to form yellow-brown fluorescent compounds. This reaction occurs inside organisms and impairs proteins. $^{2,3)}$ The accumulation of proteins impaired by Maillard reaction in vivo may be as a cause of diabetic complications and aging. ${ }^{3)}$ Aminoguanidine, which inhibits the formation of the final products of the Maillard reaction called AGE (Advanced Glycosylation Endproducts $)^{4-6)}$ is under development as a potential recessive agent against diabetes. ${ }^{5}$ )

It was found that DNA is also impaired by reducing sugars both in vitro ${ }^{7-10}$ and in vivo. ${ }^{11)}$ However, there have been relatively few reports about compounds that suppress or decrease the impairments of nucleic acids by reducing sugars. We attempted to find such a compound among the L-ascorbic acid derivatives.

\section{Materials and Methods}

Detection of plasmid impairment by glucose-6-phosphate in vitro and screening of a suppressive substance by Escherichia coli transformation. Detection of the plasmid impairment by glucose-6-phosphate (GIc-6-P) in vitro was done by the method of Bucala et al. ${ }^{2)}$ with partial modifications as follows. As L-ascorbic acid derivatives, sodium L-ascorbate (Wako Pure Chemicals), APM (magnesium L-ascorbyl-2-phosphate), calcium L-ascorbate, L-ascorbyl-2-sulfate, and sodium L-ascorbyl-2-phosphate (Showa Denko) were tested. Aminoguanidine hemisulfate (Sigma) was also used in comparison to the derivatives.

Plasmid pBR322 was prepared by cesium chloride density gradient centrifugation. ${ }^{12)}$ The $75 \mathrm{~mm}$ test compounds, $0.27 \mu \mathrm{g}$ of plasmid pBR322, and $150 \mathrm{~mm} \mathrm{D-}$ glucose-6-phosphate monosodium salt (Sigma), were incubated in a HEPES/EDTA $50 \mathrm{~mm} / 1 \mathrm{~mm}$ buffer $(\mathrm{pH} 8.0)$ at $37^{\circ} \mathrm{C}$ in the dark. All reagents were dissolved in autoclaved ion-exchanged distilled water to fully avoid contamination by DNA nucleases, and filtered through a presterilized $0.20 \mu \mathrm{m}$ cellulose acetate membrane filter (Advantec). Ten $\mu 1$ of the incubation mixtures were then sampled occasionally, and used to transform competent cells of E. coli $\mathrm{C} 600$ treated with $\mathrm{CaCl}_{2} \cdot{ }^{12}$ Cells were plated with suitable dilution on either ampicillin $(50 \mu \mathrm{g} / \mathrm{ml})$ or tetracycline $(15 \mu \mathrm{g} / \mathrm{ml})$ supplemented L-agar plates after an hour of expression at $37^{\circ} \mathrm{C}$, and the number of transformants after overnight incubation at $37^{\circ} \mathrm{C}$ was counted. As the number of transformants from ampicillinsupplemented plates showed good agreement with that from tetracycline-supplemented plates, the results from ampicillin-plates are demonstrated here. Transformation capacity was expressed as the percentage of the number of transformants against that by the plasmid without treatment of Glc-6-P kept at $4^{\circ} \mathrm{C}$ in the dark in the same buffer. Transformation efficiency per $\mu \mathrm{g}$ DNA was $9.3 \times 10^{6}-3.0 \times 10^{7}$ throughout the experiments.

Measurement of APM by HPLC. APM stability was examined by measurement using HPLC (column: Shodex NH-pack J-411 $150 \mathrm{~mm} \times 4.6 \mathrm{~mm}$ (Showa Denko)). The 
mobile phase was $0.1 \mathrm{M} \mathrm{KH}_{2} \mathrm{PO}_{4}$ ( $\mathrm{pH} 4.2$; unadjusted) with a flow rate of $0.7 \mathrm{ml} / \mathrm{min}$ at column temperature, $30^{\circ} \mathrm{C}$. The elution pattern was monitored with a UV detector at $257 \mathrm{~nm}$.

Spectroscopic studies of the interaction between Glc-6-P and dGMP (2'-deoxyguanosine 5'-monophosphate). The interaction of Glc-6-P with dGMP was observed by the change in absorbance spectra as follows. ${ }^{9}$ Solutions ( $1 \mathrm{ml}$ ) containing $10 \mathrm{~mm}$ dGMP monosodium salt (Sigma), $150 \mathrm{~mm}$ Glc-6-P, and with or without $75 \mathrm{~mm}$ APM in a HEPES/EDTA $50 \mathrm{~mm} / 0.5 \mathrm{~mm}$ buffer ( $\mathrm{pH} 8.0$ ) sterilized by filtration as described above, were incubated for a week at $37^{\circ} \mathrm{C}$ in the dark. The control solution contained Gic-6-P alone or nucleotide alone. Three hundred $\mu$ l of the incubation mixtures were sampled at the 7 th day of incubation, diluted $1: 1$ with distilled water, and their absorbance patterns between $200 \mathrm{~nm}$ and $450 \mathrm{~nm}$ were scanned and recorded with a spectrophotometer (Shimadzu UV-240)

Examination of the effects of APM on Maillard reaction of a protein. The effects of APM on the Maillard reaction of a protein (bovine serum albumin, BSA) with glucose were examined with the fluorescence spectrophotometer (F-4000, Hitachi). ${ }^{47}$ The sample mixture was a $0.5 \mathrm{~m}$ sodium phosphate buffer containing $100 \mathrm{~mm}$ BSA (A9647, Sigma), $200 \mathrm{~mm}$ D-glucose, and $3 \mathrm{~mm}$ sodium azide as a bacteriocide. Each of the reagents, $10 \mathrm{~mm}$ aminoguanidine $\cdot \mathrm{HCl}, 10 \mathrm{~mm}$ sodium L-ascorbate, and $10 \mathrm{mM}$ APM, was added to each buffer prepared to make the total volume of the incubation mixture $3 \mathrm{ml}$. In 7 and 16 days of incubation, $440 \mathrm{~mm}$ fiuorescence excited by $370 \mathrm{~nm}$ was measured using a spectrofluorimeter.

\section{Results and Discussion}

Detection of plasmid impairment by glucose-6phosphate in vitro and screening of a suppressive substance by $E$. coli transformation

As shown in Fig. 1, when the plasmid was incubated with Glc-6-P for $53.5 \mathrm{hr}$, the transformation capacity of the plasmid decreased to $1 / 10000$ of the original level due to the impairment of plsamid DNA by Glc6-P. The impairment of DNA, however, was greatly suppressed by the presence of APM. APM is a magnesium salt of an L-ascorbic acid derivative in which the hydroxyl group of the $\mathrm{C}_{2}$ position of $\mathrm{L}$-ascorbic acid is stabilized by forming a phosphoester bond.

Other ascorbic acid derivatives (sodium Lascorbate, calcium L-ascorbate, sodium Lascorbyl-2-phosphate, and L-ascorbyl-2-sul-

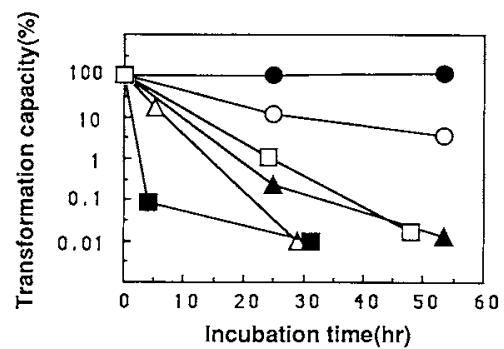

Fig. 1. Suppressibility against DNA Impairment by Glc-6-P Expressed by the Loss of pBR322 Transformation Capacity with Time after Incubation with $0 \mathrm{~mm}$ Glc-6-P (C), $150 \mathrm{~mm}$ Glc-6-P (A), $150 \mathrm{~mm}$ Glc-6-P and $75 \mathrm{~mm}$ APM (O), $150 \mathrm{~mm}$ Glc-6-P and $75 \mathrm{~mm}$ Sodium LAscorbyl-2-phosphate ( $\square$ ), $150 \mathrm{~mm}$ Glc-6-P and $75 \mathrm{~mm}$ Sodium L-ascorbate $(\triangle)$, and $150 \mathrm{~mm}$ Glc-6-P and $75 \mathrm{~mm}$ Aminoguanidine (

See the text for details.

fate) did not suppress DNA impairment by Glc-6-P. Both calcium L-ascorbate and Lascorbyl-2-sulfate showed similar behavior to sodium L-ascorbyl-2-phosphate (data not shown). Sodium L-ascorbate enhanced the plasmid impairment, indicating DNA impairments in vitro by ascorbic acid. ${ }^{13,14)}$ Aminoguanidine also enhanced the plasmid impairment (Fig. 1).

\section{Measurement of APM by HPLC}

Examination of the APM stability by HPLC showed that neither APM concentration nor retention time changed in a month at $37^{\circ} \mathrm{C}$, regardless of the presence of either Glc-6-P or the plasmid (data not shown).

Details of the mechanism of the suppressive effect by APM are not clear, and are under investigation. The specificity of APM on suppressiveness among the ascorbic acid derivatives examined suggests steric hindrance by the interaction of APM with the nucleotides against addition of Glc-6-P to nuclotides. DNA is known to be impaired by Glc-6-P in two ways ${ }^{9,10)}$ One is the formation of a Glc-6-P addition product, and the other is strand breakage by oxygen radicals. As 1 mM EDTA is present in our system, by following the result that the DNA strand breakage by the sugar phosphates is inhibited with $10 \mu \mathrm{M}$ EDTA, ${ }^{10}$ the loss of transformation capacity is not 
caused by the DNA strand breakage mainly by the oxygen radicals. This suggests that the suppressive effect of APM is not due to the trapping of oxygen radicals but by the inhibition of the formation of addition products.

\section{Effects of $A P M$ on the interaction of Glc-6-P with $d G M P$}

We investigated the effects of APM on the spectral changes produced by incubating deoxyribonucleotide and Glc-6-P in vitro. Among the four nucleotides of DNA monomers, dGMP showed most profound changes in absorbance, and therefore it was chosen for this model experiment for DNA modification by reducing sugars. As shown in Fig. 2, dGMP incubated with Glc-6-P had a clear increase of absorbance between $300-350 \mathrm{~nm}$. Co-incubation of dGMP, Glc-6-P, and $75 \mathrm{~mm}$ APM showed less absorbance than that expected from the hypothesis that no reaction occurs between the dGMP-Glc-6-P mixture and APM (Fig. 2), suggesting a possible suppression of Gic-6-P modification of dGMP by their interaction with APM. Although this is the suppressive effect observed in the monomer nucleotide and Glc-6-P system, this may partly explain the reason for the clear suppressive effect in the polynucleotide pBR322 as shown in Fig. 1.

\section{Examination of the effects of APM on Maillard reaction of a protein}

As APM showed suppression of DNA impairment by reducing sugars, it seemed interesting to investigate its effects on the nonenzymatic browning of proteins. Coincubation of BSA and glucose is accompanied by the formation of fluorescent compounds (Fig. 3). Aminoguanidine fully suppressed it. APM showed a suppressive effect which was weaker than that by aminoguanidine. Sodium L-ascorbate increased the formation of fluorescent compounds (Fig. 3).

As APM is a stable derivative of ascorbic acid with equivalent antiscorbutic activity in vivo, and no teratogenesis, mutagenesis, or

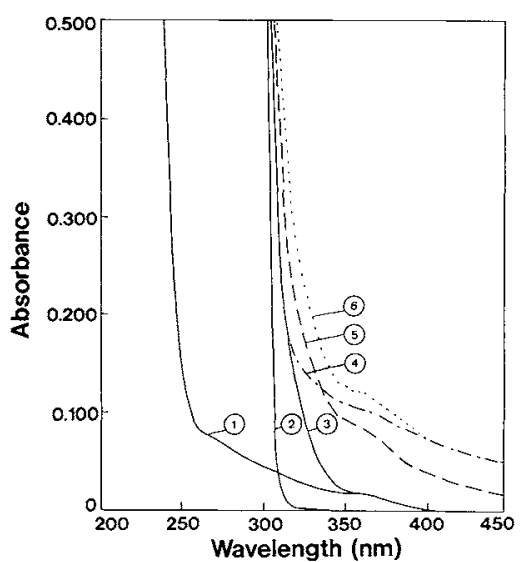

Fig. 2. UV and Visible Absorbance Spectra of a Nucleotide dGMP (2'-deoxyguanosine 5'-monophosphate) after 7 Days of Incubation at $37^{\circ} \mathrm{C}$.

(1), (2), (3), (4), (9), and (6) represent Glc-6-P, dGMP, $\mathrm{dGMP}+$ Glc-6-P, APM, dGMP + Glc-6-P + APM, and (dGMP+Glc-6-P) + APM (expected), respectively.

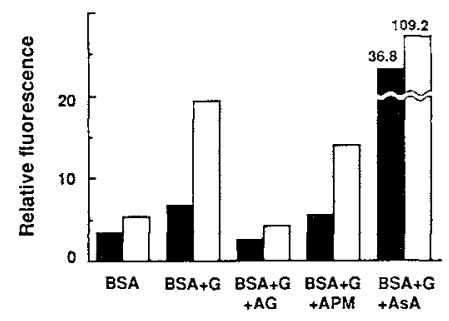

Fig. 3. Effects of AG (aminoguanidine), APM, and AsA (sodium L-ascorbate) on Advanced Glycosylation Product Formation.

"G" indicates glucose. Black and white bars denote relative fuorescence intensity after 7 and 16 days of incubation, respectively.

chronical toxicity is known, ${ }^{15-18}$ the safety in long term use is recognized. Further investigation of this APM effect in vivo by using diabetic rats will be done.

Acknowledgments. We are grateful to Dr. Masahiko Shishido and Dr. Tomiki Ikeda for lending us the spectrofluorimeter. We are also grateful to Showa Denko K. K. for providing ascorbic acid derivatives.

\section{References}

1) L. C. Maillard, C. R. Acad. Sci., 154, 66 (1912).

2) R. J. Koenig, S. H. Blobstein and A. Cerami, J. Biol. Chem., 252, 2992 (1977). 
3) V. M. Monnier, R. R. Kohn and A. Cerami, Proc. Natl. Acad. Sci. U.S.A., 81, 583 (1984).

4) M. Brownlee, H. Vlassara, A. Kooney, P. Ulrich and A. Cerami, Science, 232, 1629 (1986).

5) J. W. Baynes and V. M. Monnier (ed.), "The Maillard Reaction in Aging, Diabetes, and Nutrition," Allan R. Liss, Inc., New York, 1989, pp. 235-248.

6) M. Oimomi, N. Igaki, M. Sakai, T. Ohara, S. Baba and H. Kato, Agric. Biol. Chem., 53, 1727 (1989).

7) N. Kashimura and J. Morita, Yukigoseikagaku, 42, 523 (1984).

8) R. Bucala, P. Model, M. Ressel and A. Cerami, Proc. Natl. Acad. Sci. U.S.A., 82, 8439 (1985).

9) R. Bucala, P. Model and A. Cerami, Proc. Natl. Acad. Sci. U.S.A., 81, 105 (1984).

10) J. Morita and T. Komano, Agric. Biol. Chem. 47, 11 (1983).

11) A. T. Lee and A. Cerami, Proc. Natl. Acad. Sci.
U.S.A., 84, 8311 (1987).

12) T. Maniatis, E. F. Fritsch and J. Sambrook, "Molecular Cloning," Cold Spring Harbor Laboratory, Cold Spring Harbor, N. Y., 1982, pp. 90-91, p. 93.

13) A. Murata and K. Kitagawa, Agric. Biol. Chem., 37, 1145 (1973).

14) H. Kasai and S. Nishimura, Nucl. Acids Res., 12, 2137 (1984).

15) H. Mima, H. Nomura, Y. Imai and H. Takashima, Vitamins (Japan), 41, 387 (1970).

16) L. J. Machlin, F. Garcia, W. Kuenzig and M. Brin, Am. J. Clin. Nutr., 32, 325 (1979).

17) T. M. Brandt, C. W. Deyoe and P. A. Seib, Prog. Fish-Cult., 47, 55 (1985).

18) K. Shigueno and S. Itoh, J. World Aquaculture Soc., 19, 168 (1988). 